\title{
Phenotypic and Genotypic Diversity for Drought Tolerance among and within Perennial Ryegrass Accessions
}

\author{
Yu Cui ${ }^{1}$, Jinsheng Wang, and Xingchun Wang \\ College of Life Sciences, Shanxi Agricultural University, Taigu, Shanxi \\ Province, 030801, People's Republic of China \\ Yiwei Jiang ${ }^{2}$ \\ Department of Agronomy, Purdue University, West Lafayette, IN 47907
}

Additional index words. individual genotype, Lolium perenne, whole-plant response

\begin{abstract}
Perennial ryegrass (Lolium perenne $\mathbf{L}$.) is a popular cool-season forage and turfgrass in temperate regions. Due to its self-incompatible and out-crossing nature, perennial ryegrass may show a high degree of heterozygosity. Perennial ryegrass generally is susceptible to drought stress, but variations of drought response of individual genotypes within a particular accession or cultivar are not well understood. The objective of this study was to characterize phenotypic diversity of drought tolerance within and among accessions in relation to genetic diversity in perennial ryegrass. Five individual genotypes from each of six accessions varying in origin and growth habits were subjected to drought stress in a greenhouse. Leaf wilting, plant height, chlorophyll fluorescence (Fv/Fm) and leaf water content (LWC) differed significantly among accessions as well as among genotypes within each accession under well-watered control and drought stress conditions. Fv/Fm was highly correlated with LWC under drought stress. Genetic diversity among and within accessions were identified by using previously characterized 23 simple sequence repeat markers. Across accessions, the mean major allele frequency, gene diversity, and heterozygosity values were $0.66,0.43$, and 0.66 , respectively. Accessions with closer genetic distance generally had similar drought responses, while accessions with greater genetic distance showed distinct drought tolerance. Significant differences in drought tolerance among and within accessions, especially for individual genotypes within one accession, indicated that variations of drought response could be used for enhancing breeding programs and studying molecular mechanisms of stress tolerance in perennial ryegrass.
\end{abstract}

Water deficit has become more of a problem for production of turf and forage grasses due to regional and localized drought and increasing demands for fresh water uses in other areas. The frequency and intensity of drought stress may also increase as a result of climate change, which could further impact growth and persistence of perennial grasses. In addition, cool-season perennial grass species normally require a large amount of water to maintain growth, and it can be challenging when water availability is limited and extensive irrigation is not practical. Therefore, improvement of drought tolerance of turf and forage grasses is becoming increasingly important to minimize effects of drought on the plants and to enhance water conservation.

Phenotypic evaluation of drought response is crucial for selecting drought-tolerant materials for breeding programs. At whole plant

\footnotetext{
Received for publication 30 Apr. 2015. Accepted for publication 9 June 2015.

This research is supported by the Midwest Regional Turfgrass Foundation of Purdue University and One-Hundred Talents Program of Shanxi Province of China.

${ }^{1}$ Visiting student.

${ }^{2}$ Corresponding author. E-mail: yjiang@purdue. edu.
}

and cellular levels, fundamental responses of the perennial grass plants to drought stress have been extensively studied (DaCosta and Huang, 2006; Jiang et al., 2009; Merewitz et al., 2010; Yu et al., 2013; Zhou et al., 2013). Some drought responses used for assessing plant stress tolerance include, but are not limited to, reduced growth, photosynthesis, LWC, Fv/Fm, increased electrolyte leakage, and water use efficiency in perennial forage and turfgrass species (DaCosta and Huang, 2006; Jiang et al., 2009; Merewitz et al., 2010; Shukla et al., 2015; Xu and Zhou, 2011; Yu et al., 2013). Through evaluating LWC and Fv/Fm, drought tolerance of 57 Brachypodium distachyon accessions were differentiated, consistent with leaf wilting by visual observation (Luo et al., 2011). In a field study, large variations of $\mathrm{LWC}$ and $\mathrm{Fv} / \mathrm{Fm}$ were found among 192 accessions of perennial ryegrass (Yu et al., 2013). Whole-plant responses to drought stress provide a basis for exploring genetic variation of drought tolerance.

Perennial ryegrass is one of the most economically and environmentally important cool-season grass species. It is extensively used as a turf and forage grass around the world. Perennial ryegrass is primarily diploid $(2 n=2 x=14)$, but a tetraploid cultivar $(2 n=$ $4 x=28)$ has been developed to improve forage quality and productivity (Nair, 2004) and to enhance turf management (Richardson et al., 2007). As a self-incompatible and outcrossing species (Cornish et al., 1979), perennial ryegrass shows a high degree of genetic diversity within the population. Genetic diversity of perennial ryegrass has been characterized based on morphological traits such as seedling vigor, leaf width and forage yield (Balfourier and Charmet, 1991; Casler, 1995), isozymes (Charmet et al., 1993; Fernando et al., 1997), and molecular markers (Posselt et al., 2006; Wang et al., 2009). Furthermore, molecular markers have been successfully used for cultivar identification (Momotaz et al., 2004), assignment of individual genotypes to specific cultivars (Wang et al., 2009), quantitative trait loci mapping of key agronomic traits and disease resistance (Brazauskas et al., 2013; Navakode et al., 2009), and association mapping of drought, salt and freezing tolerance as well as spring regrowth (Aleliūnas et al., 2015; Tang et al., 2013; Yu et al., 2013, 2015). High levels of genetic diversity were observed within turf-type cultivars (Kubik et al., 2001) or within foragetype populations (Wang et al., 2009).

Phenotypic evaluation of drought response and exploration of physiological and molecular mechanisms of drought tolerance have been studied in perennial ryegrass (Huang et al., 2014; Jiang and Huang, 2001; Jiang et al., 2009; Liu and Jiang, 2010; Patel et al., 2014; Turner et al., 2012) and in turftype interspecific hybrids of meadow fescue (Festuca pratensis) with perennial ryegrass (Barnes et al., 2014). Most previous reports on drought tolerance used either seedlings from the mixed individuals (seeds) for a particular cultivar (Jiang et al., 2009; Turner et al., 2012) or seedlings from single seeds of different accessions (Liu and Jiang, 2010; Yu et al., 2013). The results did not show the stress response of individual genotypes within a cultivar or accession to drought stress conditions. Due to high level heterozygosity of perennial ryegrass and high genetic diversity within each cultivar (Kubik et al., 2001; Wang et al., 2009), it is speculated that each individual genotype (seeds) from one accession may differ in traits related to whole-plant drought tolerance. However, such research work has not been conducted in perennial ryegrass. Therefore, this experiment was designed to compare phenotypic variations of drought tolerance among and within accessions and to relate phenotypic responses to genetic diversity in perennial ryegrass accessions. Exploring variation of drought response among or within accessions is important for selecting appropriate plant materials for studying molecular response such as gene expression, conducting gene and trait association analysis, as well as for breeding purposes in perennial ryegrass.

\section{Materials and Methods}

Plant materials and growth conditions. Six accessions of diploid perennial ryegrasses were chosen for this study including 
PI598453 (Wild, Romania) and PI577265 (wild, UK), PI403847 (cultivated, Canada), PI578760 (cultivated, United States), and PI197270 (cultivated, Finland) as well as PI204085 (unknown status, Cyprus) from the USDA National Plant Germplasm System at the Western Regional Plant Introduction Station in Pullman, WA. These six accessions were selected for the study because they vary in geographical origin, growth habits, and drought tolerance assessed by seedlings grown from single seeds (Yu et al., 2013). On 1 July 2013, 10 seeds of each accession were planted in different pots $(9 \mathrm{~cm}$ deep and $10 \mathrm{~cm}$ in diameter) containing topsoil in a plant growth chamber at Purdue University in West Lafayette, IN. Our preliminary observation on simple sequence repeat (SSR) analysis revealed that five to six individual genotypes from one accession generally covered diversity of that accession. Therefore, $20 \mathrm{~d}$ after germination, five genotypes were randomly chosen for each accession with one genotype per pot. On 5 Sept. 2013, all pots were moved to a greenhouse. After 2 weeks, all genotypes from each accession were propagated with tillers to maintain genetic uniformity, with three pots for the well-watered control and three pots for drought treatment for each genotype. Each pot contained eight tillers and the same volume of soil. Plants were watered every $2 \mathrm{~d}$ and fertilized once a week with a soluble fertilizer $\left(\mathrm{N}-\mathrm{P}_{2} \mathrm{O}_{5}-\mathrm{K}_{2} \mathrm{O}, 24\right.$ 8-16) (Scotts Inc., Marysville, $\mathrm{OH}$ ) and micronutrients; they were cut once a week to the height of 6-7 cm, depending on the growth habits of each particular grass. During the growth period, the average air temperatures were $23{ }^{\circ} \mathrm{C} / 18{ }^{\circ} \mathrm{C}$ (day/night) and average daily photosynthetically active radiation (PAR) intensity was $\approx 300 \mu \mathrm{mol} \cdot \mathrm{m}^{-2} \cdot \mathrm{s}^{-1}$ in the greenhouse. All plants were well watered before initiation of drought stress.

Drought treatment. Drought stress began on 19 Oct. 2013 (110 d after seeding) and ended on 24 Oct. 2013, lasting for 6 d. Drought stress was imposed by withholding water from the grasses until permanent wilting occurred to most of the plants (the leaves were no longer rehydrated at night and in the morning), particularly for susceptible accessions. All the plants were exposed to drought stress for the same amount of time. The control plants received regular irrigation during the treatment period. At the end of treatment, drought-stressed plants were rewatered to allow recovery for $5 \mathrm{~d}$. During the time of stress and recovery, air temperatures and PAR intensity were similar to the conditions before drought stress.

Whole-plant measurements. Leaf wilting was visually rated on a scale of 0 (no observable wilting), 1 (slightly wilted), 2 (moderately wilted) to 3 (severely wilted). Leaf wilting assessment for each genotype was calculated by averaging the drought values at 4,5 , and $6 \mathrm{~d}$. At the end of drought stress, plant height (HT) was recorded. Leaf photochemical efficiency was determined by measuring $\mathrm{Fv} / \mathrm{Fm}$ on randomly selected leaves

Table 1. Accession comparisons in plant height (HT), chlorophyll fluorescence (Fv/Fm) and leaf water content (LWC) under the well-watered control and drought stress and leaf wilting under drought stress.

\begin{tabular}{llllll}
\hline Treatment & Accession & HT $(\mathrm{cm})$ & Fv/Fm & LWC (\%) & Wilting \\
\hline Control & PI204085 & $15.8 \mathrm{a}^{\mathrm{z}}$ & 0.827 & 85.1 & - \\
& PI598453 & $15.1 \mathrm{ab}$ & 0.826 & 83.2 & - \\
& PI403847 & $15.1 \mathrm{ab}$ & 0.826 & 83.9 & - \\
& PI577265 & $14.7 \mathrm{~b}$ & 0.827 & 83.4 & - \\
& PI578760 & $14.4 \mathrm{~b}$ & 0.830 & 84.6 & $2.0 \mathrm{a}$ \\
& PI197270 & $14.3 \mathrm{~b}$ & 0.827 & $56.9 \mathrm{c}$ & $0.75 \mathrm{~b}$ \\
Drought & PI204085 & $11.8 \mathrm{~b}$ & $0.715 \mathrm{c}$ & $75.5 \mathrm{a}$ & $1.2 \mathrm{~b}$ \\
& PI598453 & $12.5 \mathrm{ab}$ & $0.819 \mathrm{ab}$ & $70.4 \mathrm{ab}$ & $1.1 \mathrm{~b}$ \\
& PI403847 & $12.6 \mathrm{ab}$ & $0.808 \mathrm{ab}$ & $68.1 \mathrm{~b}$ & $0.83 \mathrm{~b}$ \\
& PI577265 & $12.4 \mathrm{ab}$ & $0.793 \mathrm{~b}$ & $74.0 \mathrm{ab}$ & $1.3 \mathrm{~b}$ \\
\hline
\end{tabular}

${ }^{\mathrm{z}}$ Means followed by the same letter in each column for a given treatment are not significantly different at $P<0.05$. Data were analyzed by pooled individual genotypes from each accession.

Table 2. Correlation coefficients among traits in perennial ryegrass accessions under drought stress.

\begin{tabular}{lllll}
\hline Trait & Wilting & HT & Fv/Fm & LWC \\
\hline Wilting & $-0.65^{* *}$ & & \\
HT & $-0.85^{* * *}$ & $0.53 *$ & \\
Fv/Fm & $-0.82 * * *$ & $\mathrm{NS}^{\mathrm{z}}$ & $0.88 * * *$ & \\
LWC & L & & \\
\hline
\end{tabular}

$\mathrm{HT}=$ plant height; Fv/Fm = chlorophyll fluorescence; LWC = leaf water content.

${ }^{\mathrm{z}} \mathrm{NS}=$ not significant.

$*, * *, * * *$ indicate significance at $P<0.05,0.01$, and 0.001 , respectively. Data averaged across three replications of individual genotypes for all accessions. $\mathrm{N}=30$.
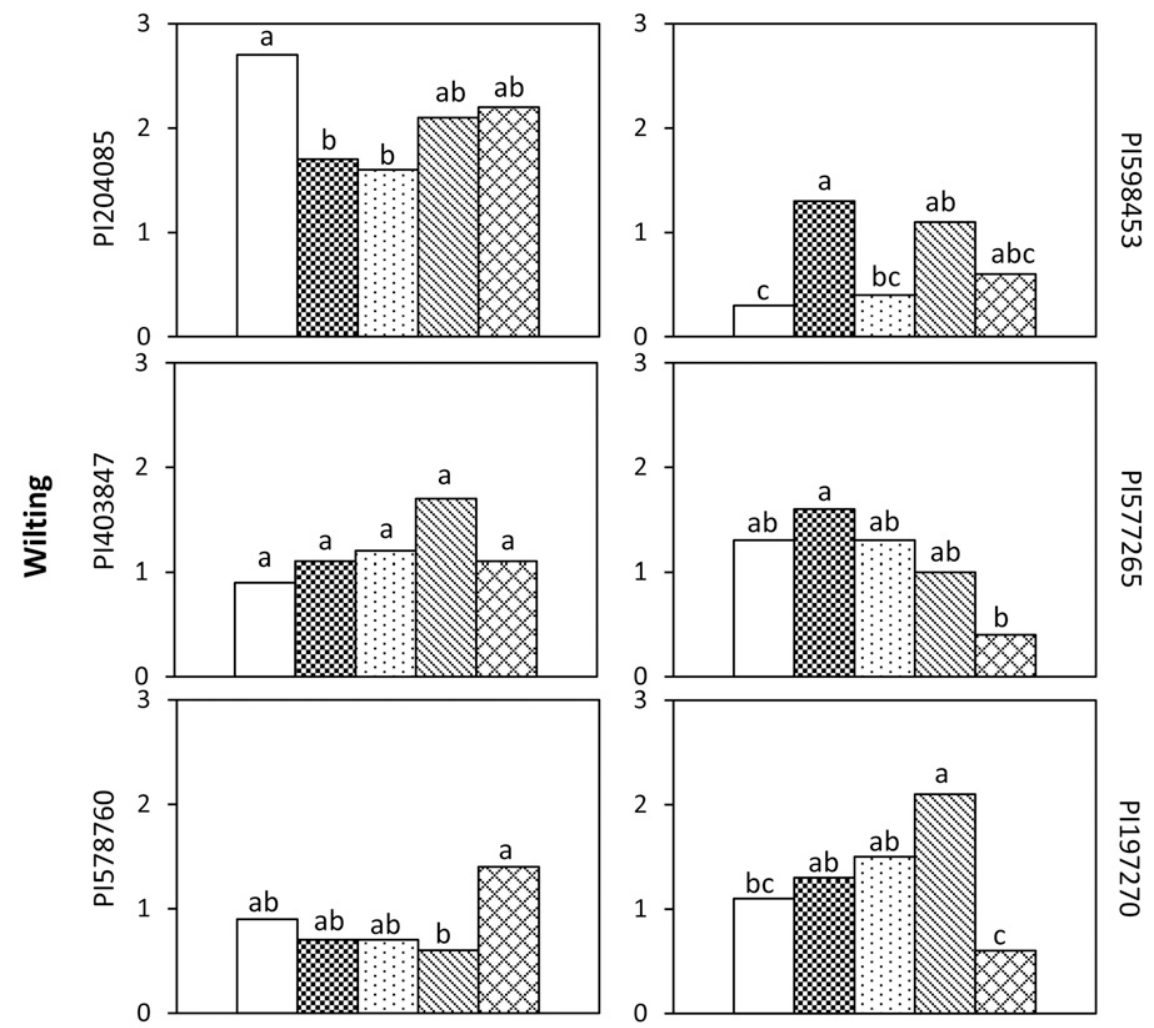

Individual genotypes

Fig. 1. Leaf wilting ratings of individual genotypes for each accession under drought stress. Means followed by the same letter within each accession are not significantly different at $P<0.05$.

in each pot using a fluorescence meter (OS-30P; OPTI-Sciences, Hudson, NH) at night after plants were adapted in darkness for an hour. Plants were cut $6-7 \mathrm{~cm}$ above the soil surface and leaf tissues after cutting dried in an oven at $75{ }^{\circ} \mathrm{C}$ for $72 \mathrm{~h}$, and then plant dry weight (DW) was measured. Leaf water content was determined according to the following equation: $\mathrm{LWC}=(\mathrm{FW}-\mathrm{DW}) / \mathrm{FW} \times 100$ where $\mathrm{FW}$ is the leaf fresh weight and DW is the dry 


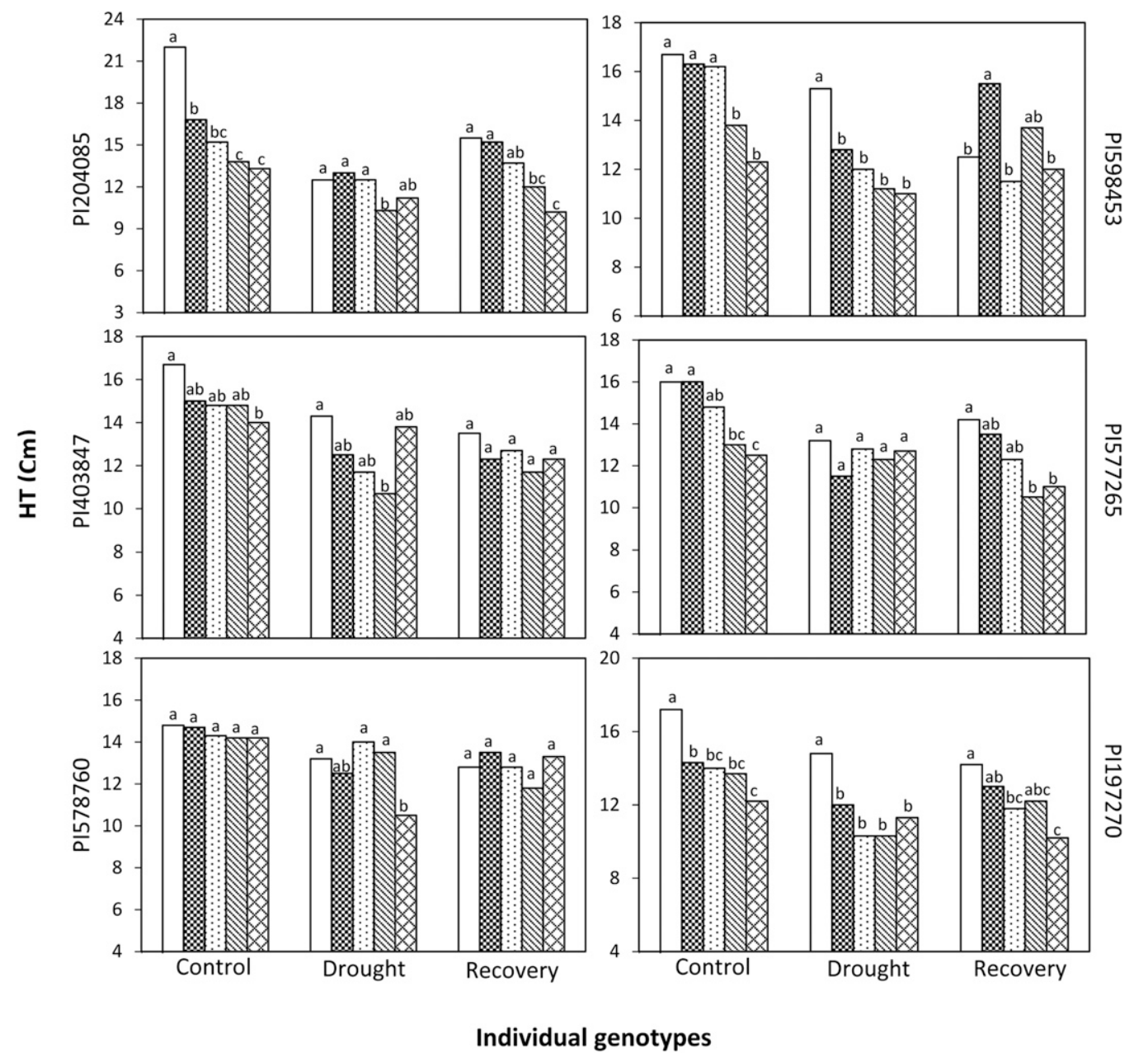

Fig. 2. Plant height (HT) of individual genotypes for each accession under the well-watered control, drought, and recovery conditions. Means followed by the same letter within each treatment for a given accession are not significantly different at $P<0.05$.

weight. Plants were re-watered after harvesting, and HT, LWC and Fv/Fm were measured again after recovery.

DNA isolation and SSR analysis. Young leaves of each genotype were collected, frozen in liquid nitrogen, and stored at $-80{ }^{\circ} \mathrm{C}$ until further use. Total genomic DNA for each individual genotype was isolated using DNeasy Plant Mini Kit (Qiagen Inc., Valencia, CA). DNA concentration was quantified using a NanoDrop ND-1000 spectrophotometer (NanoDrop Technologies Inc., Rockland, DE) and diluted to $15 \mathrm{ng} \cdot \mu \mathrm{L}^{-1}$ for polymerase chain reaction (PCR). Based on our previous results by $\mathrm{Yu}$ et al. (2013), 23 clean SSR markers representing 7 chromosomes in perennial ryegrass were selected and screened in all genotypes from each accession (Supplemental Table 1). Each 20- $\mu \mathrm{L}$ PCR reaction consisted of $1 \times$ PCR buffer, $2.5 \mathrm{~mm} \mathrm{MgCl}_{2}, 0.2 \mathrm{~mm}$ dNTP mix, 1.0 U Taq DNA Polymerase, and 60 ng DNA. All PCR reactions were performed in a MyCycler Thermal Cycler (Bio-Rad Inc., Hercules, CA) using a touch-down program, as described by $\mathrm{Yu}$ et al. (2006). In brief, PCR was started at $95{ }^{\circ} \mathrm{C}$ for $5 \mathrm{~min}$, then ran 4 cycles at $96{ }^{\circ} \mathrm{C}$ for $1 \mathrm{~min}, 68^{\circ} \mathrm{C}$ for $5 \mathrm{~min}$, with a decrease of $2{ }^{\circ} \mathrm{C}$ in each consequent cycle; and $72{ }^{\circ} \mathrm{C}$ for $1 \mathrm{~min}, 4$ cycles of $96{ }^{\circ} \mathrm{C}$ for $1 \mathrm{~min}, 58^{\circ} \mathrm{C}$ for $2 \mathrm{~min}$, with a decrease of $2{ }^{\circ} \mathrm{C}$ in each consequent cycle; and $72{ }^{\circ} \mathrm{C}$ for $1 \mathrm{~min}$, followed by 24 cycles of $96^{\circ} \mathrm{C}$ for 1 $\min , 50{ }^{\circ} \mathrm{C}$ for $1 \mathrm{~min}, 72{ }^{\circ} \mathrm{C}$ for $1 \mathrm{~min}$, with a final extension of $72{ }^{\circ} \mathrm{C}$ for $5 \mathrm{~min}$ and $4{ }^{\circ} \mathrm{C}$ for $5 \mathrm{~min}$. The amplified fragments were separated on a 3\% agarose gel. Alleles were examined manually. Major allele frequency, heterozygosity, gene diversity, polymorphism information content (PIC), and pairwise Nei's genetic distance (Nei, 1972) were obtained using Powermarker v 3.25 (Liu and Muse, 2005).

Experimental design and statistical data analysis. The experiment was arranged in a split-plot design, with drought treatment for the main plot and accession for the subplot. Each genotype from all accessions was randomly assigned within each treatment and each treatment was replicated three times. Statistical analysis was performed with Statistical Analysis System (SAS) program (version 9.1; SAS Institute, Cary, NC). The means of the trait for the treatment and grasses were separated using least significant difference at a significance level of 0.05 . Data averaged across individual genotypes for all accessions were used for analysis of correla- tion coefficients $(r)$ by using the SAS program.

\section{Results and Discussion}

Analysis of variance. Significant treatment effects were found for HT, Fv/Fm, and LWC as well as for recovered HT (RHT), Fv/Fm (R-Fv/Fm), and LWC (R-LWC). Significant accession effects were noted for Fv/Fm and LWC. Significant treatment by accession interactions was also shown in HT, $\mathrm{Fv} / \mathrm{Fm}$, and LWC.

Drought response across accessions. Under well-watered control, accessions had similar Fv/Fm and LWC values, but differed in HT (Table 1). Accession HT ranged from $15.8 \mathrm{~cm}$ (PI204085) to $14.3 \mathrm{~cm}$ (PI197270). However, significant differences in leaf wilting, HT, Fv/Fm, and LWC were observed in accessions exposed to drought stress (Table 1). Specifically, under stress, HT ranged from $12.7 \mathrm{~cm}$ (PI578760) to $11.8 \mathrm{~cm}$ (PI204085 and PI197270), Fv/Fm ranged from 0.82 (PI578760) to 0.72 (PI204085), and LWC ranged from $75.5 \%$ (PI598453) to $56.9 \%$ (PI204085). PI204085 showed the highest leaf wilting value of 2.0 , while PI598453 had the lowest value of 0.75 


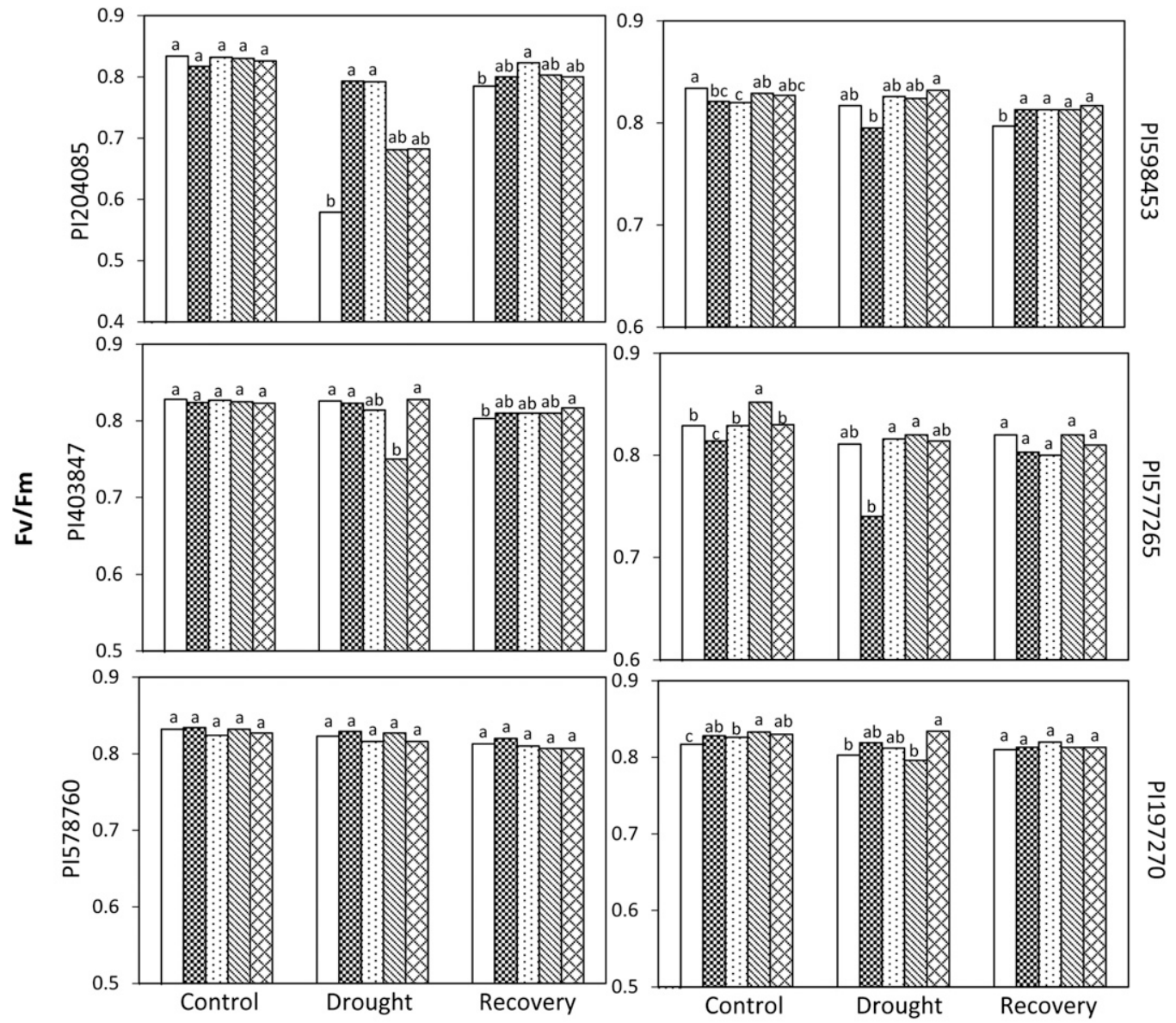

Individual genotypes

Fig. 3. Chlorophyll fluorescence (Fv/Fm) of individual genotypes for each accession under the well-watered control, drought and recovery conditions. Means followed by the same letter within each treatment for a given accession are not significantly different at $P<0.05$.

(Table 1). The results indicated that drought stress decreased HT and LWC and variations of drought response were found across accessions. Leaf wilting, Fv/Fm, and LWC provide rapid and easy measurements for whole-plant responses, particularly when large samplings are made. Thus, these parameters have been used to screen droughttolerant plant material and characterize drought tolerance at whole-plant level (Jansen et al., 2009; Luo et al., 2011; O’Neill et al., 2006; Yu et al., 2013).

Leaf wilting is an indicator of plant morphological changes due to cell dehydration and loss of turgor. It is also known that changes in LWC reflect the responses of whole plant to drought stress (Jiang et al., 2009; Luo et al., 2011; Matin et al., 1989). Relatively lower leaf wilting and higher LWC values in PI598453 and PI578760 indicate that maintenance of LWC contributes to the superior drought tolerance of perennial ryegrass accessions.

Correlations among the traits across accessions. Across genotypes of all accessions, leaf wilting was negatively correlated with HT $(r=-0.65), \mathrm{Fv} / \mathrm{Fm}(r=-0.85)$, and LWC $(r=-0.82)$ under drought stress (Table 2). Positive correlations were found between HT and Fv/Fm $(r=0.53)$ and between $\mathrm{Fv} / \mathrm{Fm}$ and LWC $(r=0.88)$, but not between HT and LWC. However, no significant correlations were identified under well-watered control (data not shown). A strong correlation between $\mathrm{LWC}$ and $\mathrm{Fv} / \mathrm{Fm}$ under drought stress supported that LWC and $\mathrm{Fv} / \mathrm{Fm}$ accounted for natural variation of drought tolerance in grass plants (Luo et al., 2011; Yu et al., 2013).

Genotypic variation within accessions. Large variations of all traits were found among genotypes within each accession under both control and drought stress. Individual genotypes significantly differed in leaf wilting in all accessions except for PI403847 exposed to drought (Fig. 1). PI204085 had more severe leaf wilting than other accessions; however, leaf wilting varied considerably among genotypes in PI598453 and PI197270. No leaf wilting was observed for all plants after recovery (data not shown).

Plant height was significantly different among individual genotypes for all accessions except for PI57860 under control and PI577265 under drought conditions (Fig. 2). Under well-watered control, the largest variation of HT among individual genotypes was found in PI204085 and the least in PI578760; however, the largest and least variations of HT were observed in PI204085 and PI577265 exposed to drought stress, respectively. Specifically, HT ranged from 13.3 to $22 \mathrm{~cm}$ for PI204085, 12.3 to $16.7 \mathrm{~cm}$ for PI598453, 14 to $16.7 \mathrm{~cm}$ for PI403847, 12.5 to $16 \mathrm{~cm}$ for PI577265, 14.2 to $14.8 \mathrm{~cm}$ for PI578760, and 12.2 to $17.2 \mathrm{~cm}$ for PI197270 under control condition, while HT ranged from 10.3 to $14.8 \mathrm{~cm}$ for PI204085, 11 to $15.3 \mathrm{~cm}$ for PI598453, 10.7 to $14.3 \mathrm{~cm}$ for PI403847, 11.5 to $13.2 \mathrm{~cm}$ for PI577265, 10.5 to $14 \mathrm{~cm}$ for PI578760, and 10.3 to $14.8 \mathrm{~cm}$ for PI197270 under drought stress. After recovery, HT differed in genotypes for all accessions except for PI403847 and PI578760. The largest variation of HT among genotypes after recovery was shown in PI204085 followed by PI598453 and PI197270.

For the control plants, Fv/Fm was unaffected by genotypes in PI204085, PI403847, and PI578760, but differed in PI598453, PI577265, and PI197270, although differences were minor among genotypes (Fig. 3). Under drought stress, genotypes from all accessions significantly differed in $\mathrm{Fv} / \mathrm{Fm}$ except for PI578760. In particular, $\mathrm{Fv} / \mathrm{Fm}$ ranged from 0.58 to 0.79 for PI204085, 0.75 to 0.83 for PI403847, and 

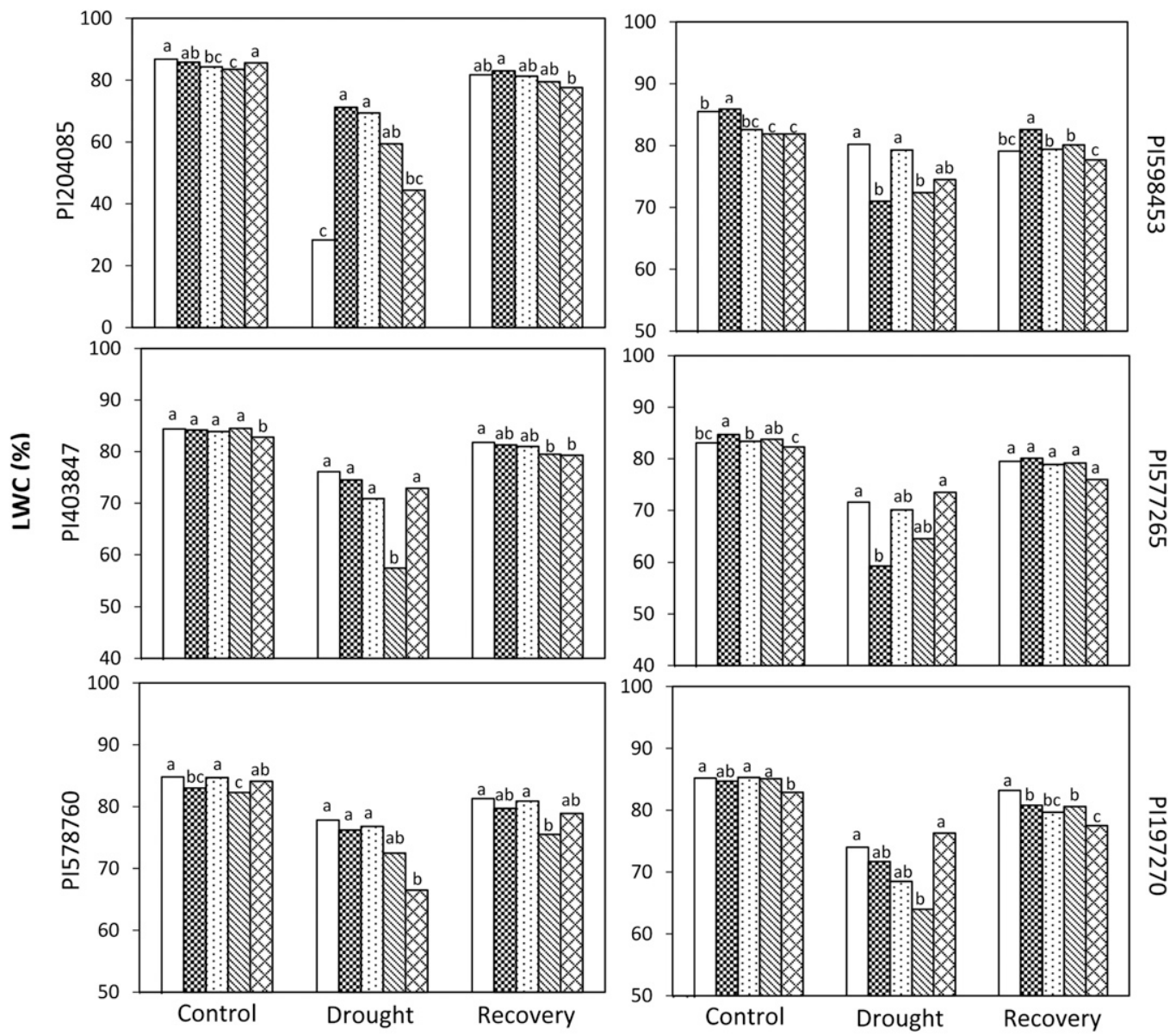

Individual genotypes

Fig. 4. Leaf water content (LWC) of individual genotypes for each accession under the well-watered control, drought and recovery conditions. Means followed by the same letter within each treatment for a given accession are not significantly different at $P<0.05$.

Table 3. Summary statistics among and within perennial ryegrass accessions.

\begin{tabular}{|c|c|c|c|c|c|c|c|}
\hline Statistics (mean) & All accession & PI204085 & PI598453 & PI403847 & PI577265 & PI578760 & PI197270 \\
\hline Heterozygosity & 0.66 & 0.50 & 0.71 & 0.70 & 0.68 & 0.73 & 0.63 \\
\hline PIC & 0.33 & 0.28 & 0.33 & 0.31 & 0.32 & 0.33 & 0.30 \\
\hline
\end{tabular}

$\mathrm{PIC}=$ polymorphism information content.

Table 4. Pairwise Nei's genetic distance among perennial ryegrass accessions.

\begin{tabular}{lcccccc}
\hline Accession & PI204085 & PI598453 & PI403847 & PI577265 & PI578760 & PI197270 \\
\hline PI204085 & & & & & & \\
PI598453 & 0.074 & & & & & \\
PI403847 & 0.061 & 0.051 & & & & \\
PI577265 & 0.058 & 0.060 & 0.063 & & & \\
PI578760 & 0.079 & 0.058 & 0.070 & 0.017 & \multirow{2}{*}{0.066} & \\
PI197270 & 0.049 & 0.036 & 0.056 & 0.072 & \\
\hline
\end{tabular}

0.74 to 0.82 for PI577265, respectively. After recovery, significant differences in $\mathrm{Fv} / \mathrm{Fm}$ were still observed in genotypes for PI204085, PI598453, and PI403847.

Leaf water content was significantly different among individual genotypes for all accessions, regardless of the treatments (Fig. 4). Plants were all turgid when receiving normal irrigation as well as after recovery, although differences in LWC among genotypes were noted for all accessions.
However, when plants were exposed to drought stress, individual genotypes within each accession differed substantially in LWC. Specifically, LWC ranged from $28.3 \%$ to $71.2 \%$ for PI204085, $71 \%$ to $80.2 \%$ for PI598453, $57.5 \%$ to $76.1 \%$ for PI403847, $59.3 \%$ to $71.6 \%$ for PI577265, $66.5 \%$ to $77.8 \%$ for PI578760, and $64 \%$ to $74 \%$ for PI197270; with the largest variation shown in PI204085.
Genotypic variations of drought responses have been characterized in annual and perennial plant species (DaCosta and Huang, 2006; Jiang et al., 2009; Jiang et al., 2010; Luo et al., 2011; Merewitz et al., 2010; Ober and Luterbacher, 2002). In perennial grass species, drought responses of individual genotypes within one accession or cultivar have not been extensively evaluated. In this study, variations of drought responses were found among individual genotypes for some accessions. The results demonstrated a range of drought responses of individual genotypes within one particular accession. Such variations could be useful for selecting individual plants for illustrating molecular responses to drought stress and for genetically improving drought tolerance of perennial ryegrass. Genetic variation in a population is derived from a wide assortment of genes and alleles. Outcrossing mating could be one key factor that 
causes genotypic variation of drought tolerance. Outcrossing increases genetic diversity within an accession (Cornish et al., 1979; Kubik et al., 2001; Wang et al., 2009). As a result, each genotype in the population can have a different fitness for that particular environment. Other factors such as selection and distribution might also play a role in contributing to the diverse responses of genotypes.

SSR diversity and genetic distance. Across all accessions, the mean MAF was 0.66 , ranging from 0.52 to 0.88 (Table 3 ). Gene diversity ranged from 0.21 to 0.50 with a mean of 0.43 , heterozygosity ranged from 0.10 to 0.97 with a mean of 0.66 , and PIC ranged from 0.18 to 0.37 with a mean of 0.33 .

Within accessions, the mean MAF was $0.75,0.63,0.65,0.65,0.67,0.62$ and gene diversity was $0.34,0.42,0.40,0.42,0.43$, and 0.39 for PI204085, PI598453, PI403847, PI577265, PI578760, and PI197270, respectively (Table 3). PI578760 exhibited higher heterozygosity with a mean of 0.73 , followed by PI598453 (0.71), PI403847 (0.70), PI577265 (0.68), PI197270 (0.63), and PI204085 (0.50). The mean PIC was 0.28 , $0.33,0.31,0.32,0.33$, and 0.30 for PI204085, PI598453, PI403847, PI577265, PI578760, and PI197270, respectively.

The genetic distance calculated by Nei's distance was larger between PI204085 and PI578760 (0.079) and between PI204085 and PI598453 (0.074), while a smaller genetic distance was identified between PI577265 and PI578760 (0.017) and between PI598453 and PI197270 (0.036) (Table 4). Comparing genetic distance among accessions, PI204805 was closer to PI197270. Moreover, both accessions showed more severe leaf wilting (Table 1). The larger genetic distances between PI204085 and PI598453 as well as between PI204085 and PI578760 were also consistent with their distinct values of leaf wilting and LWC. The results indicated that origin and genetic distance of accessions might differentiate drought responses of perennial ryegrass accessions.

In conclusion, leaf wilting, HT, Fv/Fm, and LWC varied significantly among and within accessions of perennial ryegrass under well-watered control and drought conditions. Fv/Fm was highly correlated with LWC under drought stress. The genetic distance among accessions was generally consistent with their drought tolerance. Particularly, significant differences in drought responses were identified among individual genotypes within a particular accession, suggesting that phenotypic and genotypic variations of drought responses could be used for enhancing breeding programs and studying molecular mechanisms of drought tolerance.

\section{Literature Cited}

Aleliūnas, A., K. Jonavičienè, G. Statkevičiūtè, D. Vaitiekūnaitè, V. Kemešyte, T. Lübberstedt, and G. Brazauskas. 2015. Association of single nucleotide polymorphisms in LPIRII gene with freezing tolerance traits in perennial ryegrass. Euphytica 204:523-534.

Balfourier, F. and G. Charmet. 1991. Relationship between agronomic characters and ecogeographical factors in a collection of French perennial ryegrass populations. Agronomie 11:645-657.

Barnes, B.D., D. Kopecký, A.J. Lukaszewski, and J.H. Baird. 2014. Evaluation of turf-type interspecific hybrids of meadow fescue with perennial ryegrass for improved stress tolerance. Crop Sci. 54:355-365.

Brazauskas, G., Y. Xing, B. Studer, B. Schejbel, U. Frei, P.R. Berg, and T. Lübberstedt. 2013 Identification of genomic loci associated with crown rust resistance in perennial ryegrass (Lolium perenne L.) divergently selected populations. Plant Sci. 208:34-41.

Casler, M.D. 1995. Patterns of variation in a collection of perennial ryegrass accessions. Crop Sci. 35:1169-1177.

Charmet, G., F. Balfourier, and C. Ravel. 1993. Isozyme polymorphism and geographic differentiation in a collection of French perennial ryegrass populations. Genet. Resources Crop Evol. 40:77-89.

Cornish, M.A., M.D. Hayward, and M.J. Lawrence. 1979. Self-incompatibility in ryegrass. I. Genetic control in diploid Lolium perenne L. Heredity 43:95-106.

DaCosta, M. and B. Huang. 2006. Deficit irrigation effects on water use characteristics of bentgrass species. Crop Sci. 46:1779-1786.

Fernando, W.M.U., M.D. Hayward, and M.J. Kearsey. 1997. Isozyme and quantitative traits polymorphisms in European provenances of perennial ryegrass (Lolium perenne L.). Euphytica 93:263-269.

Huang, L., H. Yan, X. Jiang, G. Yin, X. Zhang, X. Qi, Y. Zhang, Y. Yan, X. Ma, and Y. Peng. 2014. Identification of candidate reference genes in perennial ryegrass for quantitative RT-PCR under various abiotic stress conditions. PLoS One 9:e93724.

Jansen, M., F. Gilmer, B. Biskup, K.A. Nagel, U. Rascher, A. Fischbach, S. Briem, G. Dreissen, S. Tittmann, S. Braun, I. De Jaeger, M. Metzlaff, U. Schurr, H. Scharr, and A. Walter. 2009. Simultaneous phenotyping of leaf growth and chlorophyll fluorescence via GROWSCREEN FLUORO allows detection of stress tolerance in Arabidopsis thaliana and other rosette plants. Funct. Plant Biol. 36:902-914.

Jiang, Y. and B. Huang. 2001. Responses of photosynthesis and water relations to heat stress alone or in combination with drought: A comparison of tall fescue and perennial ryegrass. HortScience 36:682-686.

Jiang, Y., E. Watkins, S. Liu, X. Yu, and N. Luo. 2010. Antioxidative responses and candidate gene expression in prairie junegrass under drought. J. Amer. Soc. Hort. Sci. 135:303-309

Jiang, Y., H. Liu, and V. Cline. 2009. Correlations of leaf relative water content, canopy temperature, and spectral reflectance in perennial ryegrass under water deficit conditions. HortScience 44:459-462.

Kubik, C., M. Sawkins, W.A. Meyer, and B.S. Gaut. 2001. Genetic diversity in seven perennial ryegrass (Lolium perenne L.) cultivars based on SSR markers. Crop Sci. 41:15651572 .

Liu, K. and S.V. Muse. 2005. PowerMarker: Integrate analysis environment for genetic marker data. Bioinformatics 21:2128-2129.

Liu, S. and Y. Jiang. 2010. Identification of differentially expressed genes in perennial ryegrass under drought stress. Physiol. Plant 139:375-387.

Luo, N., J. Liu, X. Yu, and Y. Jiang. 2011. Natural variation of drought response in Brachypodium distachyon. Physiol. Plant. 141:19-29.

Matin, M.A., J.H. Brown, and H. Ferguson. 1989. Leaf water potential, relative water content, and diffusive resistance as screening techniques for drought resistance in barley. Agron. J. 81:100-105.

Merewitz, E., M. William, B. Stacy, and B. Huang. 2010. Drought stress responses and recovery of Texas $\times$ Kentucky hybrids and kentucky bluegrass genotypes in temperate climate conditions. Agron. J. 102:258-268.

Momotaz, A., J.W. Forster, and T. Yamada. 2004. Identification of cultivars and accessions of Lolium, Festuca and Festulolium hybrids through the detection of simple sequence repeat polymorphism. Plant Breed. 123:370-376.

Nair, R.M. 2004. Developing tetraploid perennial ryegrass (Lolium perenne L.) populations. N. Z J. Agr. Res. 47:45-49.

Navakode, S., A. Weidner, U. Lohwasser, M.S Röder, and A. Börner. 2009. Molecular mapping of quantitative trait loci (QTLs) controlling aluminum tolerance in bread wheat. Euphytica 166:283-290.

Nei, M. 1972. Genetic distance between populations. Amer. Naturalist 106:283-292.

Ober, E.S. and M.C. Luterbacher. 2002. Genotypic variation in drought tolerance of Beta vulgaris. Ann. Bot. 89:917-924.

O’Neill, P.M., J.F. Shanahan, and J.S. Schepers. 2006. Use of chlorophyll fluorescence assessments to differentiate corn hybrid response to variable water conditions. Crop Sci. 46:681687.

Patel, M., S. Milla-Lewis, W. Zhang, K. Templeton, W.C. Reynolds, K. Richardson, M. Biswas, M.C. Zuleta, R.E. Dewey, R. Qu, and P. Sathish. 2014. Overexpression of ubiquitin-like $L p H U B 1$ gene confers drought tolerance in perennial ryegrass. Plant Biotechnol. J. 13:689-699

Posselt, U.K., P. Barre, G. Brazauskas, and L.B. Turner. 2006. Comparative analysis of genetic similarity between perennial ryegrass genotypes investigated with AFLPs, ISSRs, RAPDs and SSRs. Czech. J. Genet. Plant Breed. 42:8794.

Richardson, M.D., K.W. Hignight, E.H. Walker, C.A. Rodgers, D. Rush, J.H. McCalla, and D.E. Karcher. 2007. Meadow fescue and tetraploid perennial ryegrass - two new species for overseeding dormant bermudagrass turf. Crop Sci. 47:83-90

Shukla, V., Y. Ma, and E. Merewitz1. 2015. Creeping bentgrass responses to drought stress and polyamine application. J. Amer. Soc. Hort. Sci. 140:94-101.

Tang, J., X. Yu, N. Luo, F. Xiao, J.J. Camberato, and Y. Jiang. 2013. Natural variation of salinity response, population structure and candidate genes associated with salinity tolerance in perennial ryegrass accessions. Plant Cell Environ. 36:2021-2033.

Turner, L.R., M.M. Holloway-Phillips, R.P. Rawnsley, D.J. Donaghy, and K.G. Pembleton. 2012. The morphological and physiological responses of perennial ryegrass (Lolium perenne L.), cocksfoot (Dactylis glomerata L.) and tall fescue (Festuca arundinacea Schreb.; syn. Schedonorus phoenix Scop.) to variable water availability. Grass Forage Sci. 67:507-518.

Wang, J., M.P. Dobrowolski, N.O.J. Cogan, J.W. Forster, and K.F. Smith. 2009. Assignment of individual genotypes to specific forage 
cultivars of perennial ryegrass based on SSR markers. Crop Sci. 49:49-58.

$\mathrm{Xu}, \mathrm{Z}$. and G. Zhou. 2011. Responses of photosynthetic capacity to soil moisture gradient in perennial rhizome grass and perennial bunchgrass. BMC Plant Biol. 11:21.

Yu, J., G. Bai, S. Cai, and T. Ban. 2006. Markerassisted characterization of Asian wheat lines for resistance to fusarium head blight. Theor. Appl. Genet. 113:308-320.

Yu, X., G. Bai, S. Liu, N. Luo, Y. Wang, D.S. Richmond, P.M. Pijut, S.A. Jackson, J. Yu, and Y. Jiang. 2013. Association of candidate genes with drought tolerance traits in diverse perennial ryegrass accessions. J. Expt. Bot. 64:15371551.
Yu, X., P.M. Pijut, S. Byrne, T. Asp, G. Bai, and Y. Jiang. 2015. Candidate gene association mapping for winter survival and spring regrowth in perennial ryegrass. Plant Sci. 235:37-45.

Zhou, Y., C.J. Lambrides, and S. Fukai. 2013. Drought resistance of bermudagrass (Cynodon spp.) ecotypes collected from different climatic zones. Environ. Expt. Bot. 85:22-29. 